\title{
A invenção do monolinguismo e da língua nacional
}

Henrique Monteagudo (Instituto da Lingua Galega, Universidade de Santiago de Compostela)

\section{Resumo}

O monolinguismo social, longe de ser um fenômeno espontâneo, frequentemente éo resultado de uma série de operações glotopolíticas de homogeneização de populações falantes de várias línguas, um resultado que é mantido artificialmente pelo Estado. O artigo mostra como esses processos históricos se vinculam à emergência dos Estados-nação e das Nações-estado que se forjaram na Europa a partir do século XVIII, ao tempo que se espalhava a ideologia da 'língua nacional'.

Palavras-chave: Sociolinguística; Política linguística; Nacionalismo; Bilinguismo. 
No prólogo à sua conhecida obra Bilingualism, a sociolinguista Suzanne Romaine (1995) faz uma observação sobre a estranheza que causaria uma monografia intitulada Monolingualism (cf. Ellis, 2008). Por que pareceria estranho um volume de estudos sobre o monolinguismo e, em troca, a ninguém chama a atenção o título Bilinguismo na capa do livro? Porque existe um modelo normativo, tacitamente aceito e profundamente interiorizado, segundo o qual o monolinguismo é o natural, o normal, o esperável, enquanto o bilinguismo (ou o plurilinguismo) é o especial, o excepcional, o anômalo: a condição monolíngue não requer qualquer tipo de explicação, ao contrário, a condição bilíngue exige uma justificação e justifica uma pesquisa, inclusivamente um diagnóstico, ao menos em alguns casos.

O caráter reconhecidamente 'normal' do monolinguismo dos indivíduos constitui o correlato subjetivo da conceituação geralmente admitida como 'normal' do monolinguismo pluri-individual - ou melhor, coletivo. Se o indivíduo é / deve ser 'idealmente' monolíngue, é porque a formação social básica a que pertence também é / deve ser assim.

Ora, se o monolinguismo é o normal, resultam lógicas perguntas do tipo como é que chega um indivíduo a ser bilingue? $\mathrm{E}$ não menos lógicas outras do tipo como é que chega uma coletividade a ser bilíngue? O suposto de base é: todo o indivíduo e toda a comunidade nascem monolíngues e só alguns/algumas se fazem bilíngues. Daí também o desconcerto do indivíduo monolíngue perante o bilíngue, que chega até o extremo de perguntar coisas como: por que te empenhas em falar galego? Como se falar esta língua fosse expressão de uma espécie de estranha mania, e não um fato simplesmente natural para as pessoas que a aprendemos ao tempo que começamos a falar, e que a partir daí a utilizamos com uma série de pessoas com que nos relacionamos de jeito mais ou menos frequente (incluindo os nossos pais, irmãos, cônjuges e filhos).

Dada a minha condição pessoal de bilíngue, consequência de me ter criado em ambientes em que circulavam correntemente duas línguas em estreito contato (galego e castelhano), vou-me situar, a efeitos de introduzir o assunto que nos ocupa, na perspectiva justamente inversa à expressada no parágrafo anterior. Assim, vou fazer estas duas perguntas: como é que se consegue que os indivíduos se façam monolíngues? Evidentemente, criando meios sociais monolíngues. Pois bem, como é que se consegue criar ambientes sociais monolíngues?

Estas perguntas podem parecer escusadas, mas se o podem parecer, isto se deve simplesmente a que estamos mergulhados em

${ }^{1}$ Para a noção de cultura, lingứística, veja-se Schiffman 1996. uma cultura linguística ${ }^{1}$ (num autêntico paradigma ou, seguindo Foucault, epistemé) em que o monolinguismo foi construído e instaurado como a situação normal. Na verdade, a pouco que percorramos a história da própria civilização ocidental e reparemos no que acontece hoje mesmo ao longo do planeta, chegaremos à 
conclusão de que o bilinguismo e o plurilinguismo não são, de maneira nenhuma, fenômenos extraordinários.

Por sinal, na Roma antiga, as elites eram bilíngues, pois não havia cidadão romano culto que não soubesse ler e falar em grego, que, além disso, era a língua comum ou franca em toda a metade oriental do Império (PALMER, 1984). Na Europa centro-ocidental do medievo os clerici ou letrados eram necessariamente bilíngues, pois a língua culta era o latim (WOLF, 1982). Na realidade, na medida em que o latim continuou a ser a língua da alta cultura, os eruditos europeus foram obrigadamente bilíngues até o século XVIII ${ }^{2}$. A mesma Península Ibérica, por acaso no século XIII, era uma região plurilíngue, com várias línguas escritas, duas delas de ampla circulação (latim, só escrita, e árabe, falada e escrita), outra com cultivo exclusivamente literário, mas procedente de fora da Península Ibérica (o occitano), outra mais com uso ritual (o hebreu), os diversos romances em pleno processo de emergência como línguas escritas (galego-português, asturleonês, castelhano, aragonês e catalão) e ainda o basco, carente de cultivo escrito. Não esqueçamos da previsão testamentária de Afonso X, segundo a qual no seu túmulo devia figurar uma inscrição em quatro línguas: árabe, latim, hebreu e romance (MORENO FERNÁNDEZ, 2005, p. 65-124).

Com certeza, nos exemplos anteriores podem distinguir-se diversos tipos de bilinguismo, que respondem a situações bem diferentes. De uma parte, existe um bilinguismo de elite, que se consegue mediante o aprendizado formal de uma língua de cultura auxiliar, e que tradicionalmente estava reservado a grupos sociais privilegiados, como era o caso da aristocracia romana, os clérigos medievais ou os letrados da idade moderna. De outra parte, existe um bilinguismo social, que se produz mediante o contato espontâneo entre falantes de várias línguas, e que tipicamente corresponde à situações de coexistência de duas línguas espalhadas em um mesmo território e/ou duas comunidades linguísticas formando parte de uma mesma entidade política, como podia ser o caso das variedades faladas do árabe e do romance no centro e, sobretudo, no sul da península durante a Idade Média.

Num sentido em certa maneira análogo ao dito, o monolinguismo pode se estudar no plano individual e no plano social. Uma sociedade, comunidade ou país monolíngue é

$\overline{2}$ Pense-se que a obra científica mais importante de Newton, Principia Mathematica, está escrita em latim; veja-se Blair 1996 e Pantin 1995, mais em geral Burke 2004: 43-60. aquele em que só uma língua é conhecida e usada pela generalidade dos seus membros. Ora, o que queremos mostrar aqui é que o monolinguismo social, longe de ser um fenômeno espontâneo, pode ser (e frequentemente é) o resultado de uma série de operações glotopolíticas, mais ou menos deliberadas, de homogeneização de populações falantes de várias línguas, um resultado que, aliás, é mantido artificialmente pelos estados mediante políticas de exclusão de línguas outras que a 'oficial- 
${ }^{3} \mathrm{O}$ nacionalismo é tema privilegiado de pesquisa nas ciências sociais contemporâneas. Entre a ampla bibliografia relevante, selecionamos alguns títulos que nos resultaram mais reveladores. Entre os estudos antigos mas ainda úteis podemos citar Weil (1961 [1938]) e Kohn (1984 [1944]). Referência obrigada entre os atuais são Kedourie (1993 [1960]) e Smith (1976 [1971]). Especialmente úteis para nós foram Gellner (1988 [1983]), Anderson (1991 [1983]), Hobsbawn (1991 [1990]) e Thiesse (1999). Damos entre parênteses a data da primeira edição de cada obra. Uma primeira aproximação nossa a esta questão em Monteagudo (1999b). mente' reconhecida. Por outras palavras, contra o que pareceria indicar o sentido comum (a doxa, usando o termo de Bourdieu), o monolinguismo não é (ou não sempre) o estado natural das coisas, mas é o resultado de processos muito complexos, e em boa parte específicos da nossa civilização na época contemporânea. Mais concretamente, tem muito a ver com a criação dos estados nação de formato europeu, que são uns artefatos de invenção relativamente recente.

\section{Língua e identidade nacional na Europa contemporânea}

Em tempos recentes, na bibliografia antropológica e sociológica o vocábulo 'invenção' aparece em sintagmas tais como 'invenção da tradição' (The Invention of Tradition; veja-se Hobsbawm \& Ranger (eds.) 1984) ou 'invenção duma nação' (como em La invención de España; veja-se Fox, 1997), associado a certas construções culturais ou políticas, em referência a processos que se consideram típicos da modernidade, desenvolvidos a partir do século XVIII. Neste contexto, o termo 'invenção' aparece utilizado polemicamente nas controvérsias sobre a gênese das nações, dos nacionalismos e das correspondentes identidades nacionais européias (ou euro-americanas) modernas, por parte dos estudiosos que defendem pontos de vista construtivistas, e criticam as posições primordialistas ou essencialistas ${ }^{3}$.

Como é sabido, segundo os relatos tradicionais, as identidades nacionais têm uma origem remota e, em todo o caso, num momento da história passada (tipicamente, a Idade Média) ficaram fixadas num molde definitivo, que praticamente não sofreu alterações substanciais ao longo da história posterior. Segundo este ponto de vista, a nação, cada nação, tem séculos de existência, possui uma essência imutável e descansa em fundamentos permanentes e objetivos: território, raça, psicologia coletiva ou Volksgeist, unidade e originalidade cultural... Um destes fundamentos acostuma ser, tipicamente, a língua.

O construtivismo, ao contrário, propugna que as nações e as correspondentes identidades nacionais são artefatos de fabricação recente, resultados de processos característicos da modernidade, relacionados com a construção de estados nacionais e com os correspondentes processos de unificação de mercados e culturas, e particularmente, resultantes da elaboração de específicas tradições culturais, linguísticas e literárias mediante processos, tecnologias e meios de comunicação de invenção recente, apoiados na ação de aparelhos educativos estato-nacionais, difusores de línguas escritas estandardizadas graças à imprensa. Dentro do construtivismo convivem pontos de vista mais radicais com outros mais moderados, que correspondem, grosso modo, com as distintas acepções do termo invenção. 
Como é sabido, invenção procede do latim inventione, substantivo deverbal de invenire. Este verbo tem, já no latim, duas acepções de base: a) produzir uma coisa nova, não previamente existente; b) descobrir, tirar à luz algo que estava ignorado. Um construtivista radical entende a 'invenção da identidade nacional' como um processo de produção de uma novidade sem muita base real (ou inclusivamente com engano); e mesmo, em alguns casos, a partir do nada. Um construtivista moderado a entende como um processo de re-interpretação de elementos tradicionais préexistentes, elementos que ganham um novo sentido ao se articularem uns com outros de um jeito novo, ou ao se incorporarem a um contexto histórico e discursivo diferente. Quem escreve estas linhas manifesta-se partidário da segunda linha de aproximação. O que em todo o caso fica claro é que as identidades nacionais, as nações, não são entidades decantadas na Idade Média, e menos ainda entidades fixadas de uma vez e para sempre.

Em realidade, a invenção do monolinguismo é inseparável da invenção do Estado-nação (e posteriormente, como veremos, da nação-Estado). Para simplificarmos uma realidade histórica notavelmente complexa, o estado-nação típico na Europa (ou, se se prefere, o primeiro protótipo de estado-nação europeu) é o construído segundo o modelo napoleônico. A sua aparição tem a ver com a mudança de uma série de conceitos chave ao redor do poder político e a sua legitimação: no Antigo Regime, o Monarca era a personificação do estado, e recebia o poder diretamente de Deus (ou, indiretamente, através do povo). O estado do antigo regime era um estado patrimonial, propriedade da dinastia reinante.

As fronteiras dos estados mudavam conforme as alianças, matrimônios, conquistas ou compras dos seus monarcas, e em muitos casos os domínios das monarquias mesmo eram territorialmente descontínuos, e não só pela existência dos impérios ultramarinos, mas também na mesma Europa. A lealdade dos súditos a respeito dos monarcas e dos senhores era de tipo pessoal, tinha um fundamento religioso e comportava obrigas fiscais e militares. Aliás, entre o monarca e os súditos se interpunham frequentemente poderes intermédios, tais como os diversos senhorios nobiliários ou eclesiásticos. Nas ditas circunstâncias, nem existiam as condições nem a necessidade de forjar uma consciência ou uma identidade nacional, fundada numa certa homogeneidade de cultura, pela sua vez apoiada na unidade de língua.

\section{O modelo napoleônico: um estado, uma nação, uma língua}

As mudanças revolucionárias que trouxeram noções fabricadas e difundidas ao longo dos séculos XVIII e XIX tais como 'soberania nacional', 'governo do povo', 'igualdade dos cidadãos' foram as que propiciaram a aparição de consciências nacionais. Os revolucionários franceses se encontraram com a herança do 
${ }^{4}$ Interpelação ("interpellation") é uma noção introduzida por Louis Althusser (1970) como $\mathrm{um}$ mecanismo ideológico definido do seguinte jeito: "l'idéologie «agit» ou «fonctionne » de telle sorte qu'elle «recrute» des sujets parmi les individus (elle les recrute tous), ou "trans-forme» les individus en sujets (elle les transforme tous) par cette opération très précise que nous appelons l'interpellation" (49), levando em conta que, segundo o mesmo autor, «la catégorie de sujet est constitutive de toute idéologie, mais en même temps et aussitôt nous ajoutons que la catégorie de sujet n'est constitutive de toute idéologie, qu'en tant que toute idéologie a pour fonction (qui la définit) de "constituer» des individus concrets en sujets» (ibídem, 46, salientado no original). Nas ciências sociais, o uso da noção de 'interpelaçã̃o' se espalhou consideravelmente para se referir de modo geral ao processo pelo qual o sujeito se reconhece a si mesmo em uma identidade dada. estado dinástico francês, cujas fronteiras (europeias) eram o resultado mais ou menos fortuito de aquisições, conquistas e alianças das sucessivas dinastias que detiveram historicamente o trono da França. No interior dessas fronteiras se falavam várias línguas (tais como o bretão, o francês, o occitano, o basco, o catalão, o italiano, diversas variedades germânicas, desde o alemão da Alsácia até o flamengo passando pelo lorenês), e o idioma francês era falado somente na região parisina, com as suas variedades distribuídas pelas outras regiões do norte (normando, picardo, champanhês, etc). A maioria da população era analfabeta, falava dialetos locais da respectiva língua, e só uma minúscula porcentagem sabia ler e falar do francês cultivado. Aproximadamente dois terços dessa população falavam variedades de línguas outras que o francês.

Os revolucionários fundaram a ideia de nação nos princípios de soberania popular e igualdade dos cidadãos, mas ao mesmo tempo decidiram que os franceses constituíam uma nação, e para fazer realidade os ditos princípios, a nação devia ter uma cultura homogênea exprimida numa língua comum. Da noção de 'estado francês' (que correspondia ao velho estado dinástico, multi-étnico e plurilíngue) passou-se à noção de 'nação francesa', e essa nação devia se exprimir na única língua nacional, a língua francesa. Dessa maneira, empreendeu-se um processo de 'etnicização do estado': a identidade política adotava assim um fundamento étnico (GRILLO, 1989, p. 22-42). Ficava cunhado o 'modelo napoleónico': um estado > uma nação > uma língua. Daí, o objetivo programático do novo estado revolucionário francês de 'anéantir les patois', isto é, aniquilar a diversidade linguística para homogeneizar a nação francesa do ponto de vista linguístico-cultural (DE CERTEAU; JULIA; REVEL, 1975; BALIBAR; LAPORTE, 1976).

O discurso revolucionário sobre a identidade estato-nacional francesa repousava em uma operação ideológica de disfarce da realidade, utilizando para tanto uma linguagem aparentemente descritiva, que na verdade, é normativa e performativa. Na superfície, esse discurso afirmava que os franceses já eram uma nação porque possuíam uma cultura e uma língua comuns, mas o que na verdade afirmava é que os franceses deviam possuir uma língua e uma cultura comuns para chegarem a constituir uma nação; portanto, ainda não eram uma nação. O discurso sobre a nação, a língua e o estado pode ser interpretado como uma instância de interpelação $0^{4}$ as várias populações que habitavam nos territórios do velho estado dinástico são chamadas a se constituir em nação francesa, e para tanto, a abandonar as suas línguas seculares e adotarem o idioma francês.

De outra parte, a realidade do plurilinguismo é escamoteada, ocultada, negada, mas o é precisamente para que não seja visível o projeto da sua destruição. Destarte, também fica excluída 
à partida a hipótese da convivência pluralista: a necessidade de impor a língua comum se vincula necessariamente à destruição das outras línguas, sem dar sequer a oportunidade de contemplar a possibilidade de fazer compatível a diversidade linguística dos diferentes povos com a difusão de uma língua comum de intercomunicação. Nascia assim a ideologia da monoglossia, e o modelo do estado-nação monolíngue, ao tempo que se iniciava a construção discursiva da nova noção de 'língua nacional'. A diversidade línguística se tornava uma realidade anômala e disfuncional, tanto na ideologia quanto na prática. O estado ficava programaticamente vinculado ao programa de homogeneização linguística e cultural, correlativo ao de criação e difusão da língua e a cultura nacionais e a manutenção da correspondente intelectosfera ideológica e cultural que acompanha, legitimando-os, esses processos.

Os meios de que se valeu o estado nacional de novo cunho para conseguir a uniformização linguístico-cultural e a difusão das ideologias que a legitimavam, isto é, os meios de moldeamento das consciências e dos hábitos linguísticos, foram basicamente dois: de uma parte, os aparelhos do estado e a burocracia ao seu serviço (o uso administrativo da língua), da outra, e muito especialmente, o aparelho educativo sob controle do Estado (quando não diretamente estatal e centralizado), que ao longo dos séculos XIX e XX foi estendendo a sua cobertura da população infantil e juvenil e ampliando o período de permanência obrigatória.

Mas a construção do estado nacional respondeu também ao interesse de determinados grupos sociais (a grande burguesia industrial, comercial e financeira; a burocracia, o exército e outros corpos estatais; certos setores da intelectualidade), que contribuíram decisivamente neste programa de 'nacionalização'. Assim, não se pode esquecer a relevância dos meios de comunicação e em geral de todas as instituições do que Habermas denominou a 'publicidade burguesa': meetings, clubes políticos e esportivos, comemorações e festividades públicas, cassinos, tertúlias, etc. (HABERMAS, 1994). Todos estes meios contribuíram em maior ou menor medida à criação e difusão da cultura monoglóssica e à divulgação da 'língua nacional'.

O correlato na consciência individual da identidade monoglóssica do estado-nação monolíngue e a constituição de um novo sujeito é o cidadão monolíngue, interpelado para manter uma forte e unívoca lealdade àquela identidade coletiva. Um cidadão instruído e construído, tanto nas suas competências linguístico-comunicativas, quanto nas suas representações mentais e atitudes, em grande parte através do sistema educativo. De determinar os seus hábitos linguísticos se encarregaria mais bem o meio social. 


\section{O contra-modelo herderiano: uma língua, uma nação, um estado}

O modelo napoleônico foi aplicado para transformar velhos estados proto-nacionais da Europa ocidental em modernos estados-nação: primeiro a França, depois, ao menos tentativamente, a Espanha; Portugal e a Holanda, com as suas especificidades (entre outras cousas, não eram países multi-étnicos); a Grã Bretanha seguiu um caminho próprio, mas, afinal não substancialmente distinto. Mas não demorou em se gerar um contra-modelo, que aqui vamos denominar herderiano, pois a sua inspiração foi atribuída ao filósofo alemão Johann G. Herder (1744-1803) (cf. Monteagudo, 1999a). Este modelo surgiu e se espalhou na Europa central e oriental, e provocou de uma parte os movimentos de unificação de Itália e Alemanha, e de outra a desmembração de Impérios como o Haubsburgo (austríaco) e o Otomano, e a independência de países como a Noruega (arrancada antes da Dinamarca e finalmente da Suécia) ou Finlândia (que escachou primeiro da Suécia e finalmente da Rússia). Esses processos históricos foram impulsionados por movimentos nacionalistas que também estabeleceram uma relação entre a língua, a identidade nacional e o estado, mas em termos precisamente contrários ao 'modelo napoleônico' (BAGGIONI, 1997, p. 201-87).

Os nacionalismos 'irredentistas' não se apoiavam num estado pré-existente, mas aspiravam a criá-lo, por tanto, partiam de uma situação radicalmente distinta aos nacionalismos estatalistas. Quer dizer, fundavam-se na existência de comunidades étnicas englobadas em estados multiétnicos (e/ou fragmentadas politicamente), comunidades muitas vezes carentes de tradições estatais próprias e caracterizadas pela posse de uma língua própria, a qual, frequentemente carecia de tradição cultivada (mesmo, em muitos casos, era totalmente ágrafa), ainda que em alguns casos pudessem ser invocados precedentes históricos mais ou menos remotos de posse de um estado próprio ou de cultivo literário do idioma vernáculo. Esquematicamente, o raciocínio dos nacionalistas irredentistas corria em sentido inverso aos estatalistas: somos uma comunidade diferenciada porque possuímos uma língua própria e distinta, e por isso mesmo constituímos uma nação, e como tal temos direito a um estado independente. Se bem que em ocasiões, o que se reivindicava não era um estado independente, mas um estado federado em pé de igualdade com outras comunidades étnico-linguísticas.

Se no caso do nacionalismo estatalista falamos antes de um processo de 'etnicização da política', agora podemos falar da 'politização da etnicidade'. Na Europa dos séculos XIX e XX, o nacionalismo irredentista propiciou amplos movimentos de unificação nacional (Itália e Alemanha), que pela sua vez se rea- 
lizaram a custa da desaparição de unidades políticas anteriores e da desmembração de partes de territórios doutros países; mas com muita mais frequência deu azo à fragmentação de Impérios e ao nascimento de novos estados: desde a Grécia e a Polônia até a Estônia ou a Croácia. Uma solução intermédia, que podia consistir na federação igualitária das distintas comunidades etno-linguísticas, foi tentada em ocasiões e nem sempre com sucesso durável (a Suíça e em certa maneira a Bélgica podem servir de exemplos).

\section{A invenção do monolinguismo e da língua nacional}

Mas o que nos importa salientar é que, fosse pela via do modelo napoleônico, fosse pela via contrária do modelo herderiano (este em princípio mais aberto ao pluralismo), em toda a Europa acabou por se estabelecer uma associação estreita entre língua, identidade nacional e estado; e por via da regra essa associação era unívoca e excludente, quer dizer: o monolinguismo das nações e o uninacionalismo dos estados é a norma; em correspondência, fomentou-se a monolingualização das populações e dos indivíduos. Nas nações monolíngues se formaram cidadãos monolíngues. A convivência de várias línguas dentro de uma sociedade passou a ser uma raridade, uma anomalia, e com ela também os indivíduos bilíngues (exceto, claro está, o aprendizado de segundas línguas auxiliares, para o estudo, o comércio, etc.).

Portanto, a emergência dos estados nacionais, fossem do tipo napoleônico (estado > nação) fossem do tipo herderiano (nação > estado) teve um duplo efeito (sócio)linguístico: de uma parte, a política dos estados nacionais se orientou à uniformização linguística das populações mediante a imposição da língua nacional, de outra parte, a própria língua nacional foi sujeita a uma série de profundas intervenções tendentes à estandardização, tanto mais intensas quanto menos tradição de elaboração e cultivo tivesse às suas costas (por caso, as línguas ágrafas tiveram de ser dotadas de um alfabeto e normas ortográficas, etc.). Estes dois processos foram impulsionados por e acompanhados de grandes transformações na consciência linguística das respectivas comunidades idiomáticas, e em particular pela criação e difusão de ideologias e discursos legitimadores da uniformização linguística, da hegemonia da língua nacional, e da estandardização (com a correspondente preeminência da variedade padrão dessa língua). Foi assim que se inventou o monolinguismo. 


\begin{abstract}
Societal monolingualism, far from being a spontaneous phenomenon, is usually the outcome of glotopolitical interventions aimed at the uniformization of previously multilingual populations. This outcome is achieved and artificially sustained by deliberate institutional and governmental policies. This contribution explains how these historical processes are connected to the emergence of Nation-States and States-Nation established in Europe form the 18th century on. At the same time, the ideology of the 'national language' was elaborated and diseminated, so the cultural, socio-political and practical conditions for the creation of monoligual spaces were achieved.
\end{abstract}

Keywords: Sociolinguistics; Language Planning; Nationalism; Bilingualism

\title{
REFERÊNCIAS
}

ALTHUSSER, Louis. Idéologie et appareils idéologiques d'État: Notes pour une recherche, 1970. Disponível em:

http://classiques.uqac.ca/contemporains/althusser_louis/ideologie_et_AIE / ideologie_et_AIE.pdf Acesso em: 28 dez. 2009.

. Artigo originalmente publicado en La Pensée, no 151, e incluído en Louis Althusser. Positions (1964-1975). Paris: Les Éditions sociales, 1976, pp. 67-125.

ANDERSON, Benedict. Imagined Communities. London; New York: Verso, 1991.

BAGGIONI, Daniel. Langues et nations en Europe. Paris: Éditions Payot \& Rivages, 1997.

BALIBAR, Renée; LAPORTE, Dominique. Burguesía y lengua nacional. Barcelona: Avance, 1976.

BLAIR, Ann. La persistance du latin comme langue de science à la fin de la Renaissance. In: CHARTIER, Roger; CORSI, Pietro (dirs.). Sciences et langues en Europe. [Paris]: École des Hautes Études en Sciences Sociales; Centre National de la Recherche Scientifique; Muséum National d'Histoire Naturelle, 1996, pp. 21-42.

BURKE, Peter. Languages and Communities in Early Modern Europe. Cambridge: Cambridge University Press, 2004.

DE CERTAU, Michel; JULIA, Dominique; REVEL, Jacques. Une politique de la langue. La Révolution française et les patois: l'enquête de Gregoire. Paris: Gallimard, 1975. 
ELLIS, Elizabeth E. (ed.). Defining and Investigating Monolingualism In: Sociolinguistic Studies 2.3, 2008. Disponível em: http://www. equinoxjournals.com/SS/index

FOX, Inman. La invención de España. Nacionalismo liberal e identidad nacional. Madrid: Ediciones Cátedra, 1997.

GELLNER, Ernest. Nations and Nationalism. Oxford: Basil Blackwell, 1998.

GRILLO, Ralph. Dominant Languages. Language and Hierarchy in Britain and France. Cambridge: Cambridge University Press, 1989. HABERMAS, Jürgen. Historia y estructura de la opinión pública. La transformación estructural de la vida pública. Barcelona: Gustavo Gili, 1994.

HOBSBAWM, Eric. Naciones y nacionalismo desde 1780. Barcelona: Editorial Crítica, 1991.

; RANGER, Terence. The Invention of Tradition. Cambridge: Cambridge University Press, 1992.

KEDOURIE, Elie. Nationalism. Oxford: Blackwell Publishers, 1993. KOHN, Hans. Historia del nacionalismo. México / Madrid / Buenos Aires: Fondo de Cultura Económica, 1984.

MONTEAGUDO, Henrique. Nas raíces ideolóxicas do nacionalismo lingüístico: unha visita a J. G. Herder. In: ÁLVAREZ BLANCO, Rosario; VILAVEDRA, Dolores (eds.). Cinguidos por unha arela común. Homenaxe ó profesor Xesús Alonso Montero, 2 vol.. Santiago de Compostela: Universidade de Santiago de Compostela, vol. 1, 1999a, pp. 691-714.

1999b.

. Historia social da lingua galega. Vigo: Editorial Galaxia,

MORENO FERNÁNDEZ, Francisco. Historia social de las lenguas de España. Barcelona: Ariel, 2005.

PALMER, Leonard. Introducción al latín. Barcelona: Ariel, 1984.

PANTIN, Isabelle. Latin et langues vehiculaires dans la littérature scientifique européenne au début de l'époque moderne (1550-1635). In: CHARTIER, Roger; CORSI, Pietro (dirs.). Sciences et langues en Europe. [Paris]: École des Hautes Études en Sciences Sociales; Centre National de la Recherche Scientifique; Muséum National d'Histoire Naturelle, 1996, pp. 43-58.

ROMAINE, Suzanne. Bilingualism. Oxford: Blackwell, 1995.

SCHIFFMAN, Harold F. Linguistic Culture and Language Policy. London \& New York: Routledge, 1996.

SMITH, Anthony. Las teorías del nacionalismo. Barcelona: Ediciones Península, 1976.

THIESSE, Anne Marie. La création des identités nationales. Paris: Éditions du Seuil, 1999. 
WEILL, Georges. La Europa del siglo XIX y la idea de nacionalidad. México: Unión Tipográfica Editoria Hispanoamericana, 1961.

WOLFF, Philippe. Les Origines linguistiques de l'Europe occidentale. Toulouse: Association des publications de l'Université de Toulouse-Le Mirail, 1982. 